UNIVERSIDADE DE BRASÍLIA

INSTITUTO DE LETRAS

CURSO DE LETRAS - LICENCIATURA EM LÍNGUA PORTUGUESA

DEPARTAMENTO DE LINGUISTICA, LINGUAS CLÁSSICAS E PORTUGUÊS

PROJETO DE CURSO

PROFESSORA DRA ELOISA PILATI

ROSÂNGELA PEREIRA LIMA SILVA

\title{
PROPOSTA DE ATIVIDADE DIDÁTICA PARA O ENSINO DE VÍRGULA EM SÉRIES FINAIS DO ENSINO FUNDAMENTAL E ENSINO MÉDIO.
}


ROSÂNGELA PEREIRA LIMA SILVA

\section{PROPOSTA DE ATIVIDADE DIDÁTICA PARA O ENSINO DE VÍRGULA EM SÉRIES FINAIS DO ENSINO FUNDAMENTAL E ENSINO MÉDIO.}

Trabalho de Conclusão de Curso de Graduação, em forma de Artigo Científico, apresentado ao Departamento de Linguística, Línguas Clássicas e Português da Universidade de Brasília, como parte dos requisitos para obtenção do título de Licenciada em Língua Portuguesa e Respectiva Literatura.

Orientadora: Prof. ${ }^{a}$ Dr. ${ }^{a}$ Eloisa Pilati 


\section{PROPOSTA DE ATIVIDADE DIDÁTICA PARA O ENSINO DE VÍRGULA EM SÉRIES FINAIS DO ENSINO FUNDAMENTAL E ENSINO MÉDIO.}

Trabalho de Conclusão de Curso de Graduação, em forma de Artigo Científico, apresentado ao Departamento de Linguística, Línguas Clássicas e Português da Universidade de Brasília, como parte dos requisitos para obtenção do título de Licenciada em Língua Portuguesa e Respectiva Literatura.

Orientadora: Prof. ${ }^{a}$ Dr. ${ }^{a}$ Eloisa Pilati

Data:

Resultado:

Orientadora: Prof. ${ }^{a}$ Dr. ${ }^{a}$ Eloisa Pilati 
Dedico este trabalho a Deus, à minha família, meu alicerce, ao meu namorado Renato Gomes, companheiro de lutas e vitórias, e à Professora Doutora Eloisa Pilati, minha orientadora, por toda a amizade e dedicação em sua carreira de ensinar. 


\title{
PROPOSTA DE ATIVIDADE DIDÁTICA PARA O ENSINO DE VÍRGULA EM SÉRIES FINAIS DO ENSINO FUNDAMENTAL E ENSINO MÉDIO.
}

\author{
Rosângela Pereira Lima Silva * \\ Eloisa Silva Pilati* \\ Universidade de Brasília (UnB)
}

\begin{abstract}
Resumo: O presente artigo é resultado da elaboração e aplicação de uma atividade, com o objetivo de analisar se a metodologia utilizada na atividade, que se difere da utilizada pelas escolas atualmente, obtêm bons resultados e se ajudaria no aprendizado pelos alunos. O arcabouço teórico foi baseado, principalmente, em autores como Soares (2003), Chomsky (2008), Lobato(2003), Franchi (2006), dentre outros, não menos importantes. A metodologia utilizada foi a qualitativo interpretativista, que possibilita a observação, descrição e interpretação dos dados colhidos nas atividades realizadas pelos alunos. As atividades foram compostas por três etapas, cada uma trazendo um novo caso do uso da vírgula, acrescidas, ao final, por um espaço onde o aluno teria a oportunidade de avaliar a atividade respondida. Após a análise dos dados obtidos pelas respostas dos alunos e suas avaliações sobre as atividades, observamos que, em uma parte do publico observado, as atividades não obtiveram um resultado satisfatório, apesar de muitos alunos terem gostado do modelo. Em contrapartida, um segundo público, em quase sua totalidade, teve um rendimento bastante satisfatório, levando em conta que se tratava de duas realidades diferentes, o ensino público e o ensino particular, respectivamente. Apesar desse fato, nas respostas dos alunos, de ambas realidades, podemos notar que os alunos conseguiram seguir o raciocínio eliciado através das atividades, e aplicaram e/ou explicaram não da forma que esperávamos, mas com uma lógica formada que observa-se a abstração e construção do conceito e uso do determinado caso do uso da vírgula. Porém, mesmo com a construção de um raciocínio os alunos sempre se baseiam no que sempre aprenderam e escutaram, no que as gramáticas tradicionais vem pregando massivamente, e o que os professores reproduzem: que a vírgula é uma pausa.
\end{abstract}

Palavras-chave: Usos da vírgula, atividades, metodologia, letramento.

Abstract: This article is from the elaboration and implementation of an activity, aiming to examine the methodology used in the activity, which differs from that used by schools today, and get good results if it would help in learning by students. The theoretical framework was based primarily on authors such as Smith (2003), Chomsky (2008), Lobato (2003), Franchi (2006), among others, no less important. The methodology used was qualitative - interpretive, enabling the observation,

\footnotetext{
* Orientanda do Projeto de Curso de Letras, habilitação em língua portuguesa e respectiva literatura, da Universidade de Brasília (UnB). E-mail: roangel75@gmail.com
} 
description and interpretation of data collected from the activities performed by students. The activities were composed of three steps, each bringing a new case of the use of the comma, plus, eventually, a space where students have the opportunity to evaluate the activity answered. After analysis of data obtained from students' responses and their assessments on the activities, we observed that in one part of the public observed the activities did not obtain a satisfactory result, although many students have enjoyed the model. In contrast, a second audience, almost in their entirety, has had a very satisfactory performance, taking into account that they were two different realities, public education and private education, respectively. Despite this fact, the responses of the students in both realities, we note that the students could follow the reasoning elicited through the activities, and have applied and / or does not explain the way we expected, but with a logic that formed the abstraction is observed and construction of the concept and use of the particular case of the use of the comma. But even with the construction of a reasoning students are always based on who always listened and learned, as traditional grammars has been preaching massively, and that teachers reproduce: the comma is a pause.

Keywords: Uses of the comma, activities, methodology, literacy.

\section{INTRODUÇÃO.}

O ensino de língua portuguesa em nossas escolas vem encontrando alguns problemas, entre eles a metodologia que é utilizada há vários anos, e que pressupõe que o aluno não sabe as normas gramaticais e, por isso, não as utiliza, recorrendo ao método da memorização como forma de aprendizado. Essa metodologia gera o desinteresse dos alunos pela disciplina, pois esses consideram o aprendizado da língua portuguesa como um trabalho massante e cansativo. Porém, as correntes atuais de pesquisa analisam que o aluno, que vive em sociedade, possui um pré-conhecimento devido suas experiências, e por isso não necessita de uma memorização, mas sim de um raciocínio que contextualize sua experiência ao que é ensinado. A partir daí, tem-se o desafio de conciliar a prática do letramento ao ensino de língua portuguesa.

Utilizando o modelo de técnica elicitativa, proposto por Lobato (2003), foi possível aplicar uma atividade a alunos das séries finais do ensino fundamental e a alunos de ensino médio, o que possibilitou uma pesquisa de natureza qualitativa - interpretativista. Segundo Bogdan e Biklen (1982), a pesquisa qualitativa se preocupa com as perspectivas dos participantes, importando o significado que os participantes dão às suas ações e construções, assim como as análises, que são realizadas centradas nos dados e não em hipóteses. Já

\footnotetext{
** Professora Doutora em lingüística da Universidade de Brasília (UnB), orientadora do Projeto de Curso. Email: eloisapilati@gmail.com
} 
Erickson (1986) acredita que o ponto de vista dos participantes da pesquisa e seu contexto social é importante, pois a interpretação do meio em que vive terá efeito sobre suas ações. Dessa forma, a pesquisa de cunho qualitativo-interpretativista guiará a pesquisa para que essa seja realizada não de forma hipotética, mas sim com base na observação de dados de construções dos alunos e de suas conclusões em torno das atividades que responderam.

\section{FUNDAMENTAÇÃO TEÓRICA}

O letramento, segundo Soares (2003), é a prática social da leitura e da escrita, ou seja, é o uso efetivo dessas práticas. Recentemente, em uma obra ainda não publicada, Guilherme Rios, doutor em Linguística (Ph.D) pela Lancaster University, defende que a questão do letramento tem sido confundida com alfabetização: "O letramento não se restringe ao que se faz de leitura e escrita na escola, muito menos ao início de escolarização." (RIOS, N/P). Além disso:

\footnotetext{
“Assim, o termo 'letramento' estaria livre para referir-se, com certa exclusividade, ao processo por que indivíduos e coletividades passam em sua história de vida. Isto traria a vantagem de fixar a visão do letramento como algo em que as pessoas estão em constante experiência de aprendizagem, em um contínuo de mudanças, à medida que engajam em novas situações ao longo da vida.

[...]

A alfabetização passa a ser um período na história de letramento do indivíduo, podendo acontecer no interior da escola ou não. Se acontece fora da escola, o que não é muito comum, trata-se, então, de uma aprendizagem a partir da participação da pessoa em uma determinada prática, como pode acontecer, por exemplo, com fiéis não-alfabetizados que aprendem o alfabeto pela leitura e interpretação da Bíblia em círculos religiosos. Frequentemente não há, nesse caso, um treinamento sistemático onde o indivíduo é levado a fazer correlações entre o som (fonema) e a letra (grafema)." (RIOS, N/P, p.2)
}

Para melhor exemplificar, pensemos em uma pessoa que não sabe escrever, mas procura uma pessoa que sabe, e lhe dita o conteúdo de uma carta que gostaria de enviar. Essa pessoa, obviamente, é analfabeta, pois não possui o domínio da escrita. Porém, ela soube construir e esquematizar mentalmente o conteúdo da carta. Dessa forma, pode-se dizer essa pessoa é letrada, pois sabe como fazer uso do instrumento "escrita", mas entretanto, não possui o domínio do código.

Mesmo diante a diferenciação entre letramento e alfabetização, Soares diz que: 


\begin{abstract}
"Dissociar alfabetização e letramento é um equívoco porque, no quadro das atuais concepções psicológicas, lingüísticas e psicolingüísticas de leitura e escrita, a entrada da criança (e também do adulto analfabeto) no mundo da escrita se dá simultaneamente por esses dois processos: pela aquisição do sistema convencional de escrita - a alfabetização, e pelo desenvolvimento de habilidades de uso desse sistema em atividades de leitura e escrita, nas práticas sociais que envolvem a língua escrita - o letramento. Não são processos independentes, mas interdependentes, e indissociáveis: a alfabetização se desenvolve no contexto de e por meio de práticas sociais de leitura e de escrita, isto é, através de atividades de letramento, e este, por sua vez, só pode desenvolver-se no contexto da e por meio da aprendizagem das relações fonema-grafema, isto é, em dependência da alfabetização.” (SOARES, 2003, p.14)
\end{abstract}

Soares (2003) alerta, ainda, que é necessário o aprendizado de toda a complexa tecnologia envolvida no aprendizado do ato de ler e escrever, da qual o aluno necessita saber fazer seu uso, e envolver-se em suas atividades. No entanto, infelizmente, não é isso o que ocorre no ensino de nossas escolas. Temos, na educação brasileira, a tradição de ensinar a ler e a escrever, utilizando métodos de memorização, o que faz do ensino dos conteúdos algo muito mais mecânico do que cognitivo. Essa metodologia utilizada, como afirmam Travaglia, Araújo e Alvim (2007), que tem por base o estruturalismo, busca o ensino partindo da oralidade, que já é dominada pelo aluno, relacionando-a com a estrutura lingüística.

A criança, segundo Chomsky (2008), recebe geneticamente um mecanismo complexo que possibilita a aquisição de estruturas gramaticais, com uma grande rapidez, o que faz com que as informações adquiridas se alterem ao longo de sua vida. Esse mecanismo é denominado faculdade da linguagem. O estado inicial da criança se altera sob circunstâncias diferentes devido à maturação interna e às experiências externas, processo denominado aquisição da linguagem. Ou seja, a criança, desde a sua concepção possui a faculdade da linguagem, que é um fator biológico e cognitivo, inerente ao ser humano, cuja aquisição ocorre durante sua maturação e experiência externa, já que é característica própria do ser humano. Segundo o autor, "se uma criança é inserida numa situação em que há o devido estímulo, a aquisição da linguagem é algo que vai ocorrer à criança" (CHOMSKY, 2008, p. 21). Dessa forma, a língua materna da criança é resultado de seu amadurecimento, e consequiência das conclusões ou respostas aos estímulos e experiências sofridas acerca da língua adquirida, inferindo assim, em um curto tempo, na estrutura gramatical de sua língua. Sendo assim, as escolas não oferecem o estímulo necessário para que o aluno formule suas próprias conclusões e respostas a respeito da estrutura gramatical da língua, fazendo com que esse, simplesmente, reproduza um saber já construído. Precisamente com base nessa perspectiva é que o ensino de vírgula tem sido trabalho nas escolas. Tendo por base o 
conceito, formado de forma superficial, das gramáticas tradicionais, o aluno abstrai a idéia de que o uso da vírgula está intimamente ligado à fala, conceito que lhe foi anteriomente transmitido, promovendo o desconhecimento, por parte do aluno, acerca da função dessa na estrutura gramatical da língua.

\section{A VÍRGULA, MUITO ALÉM DA PAUSA.}

Cunha e Cintra (2001) conceituam a vírgula como "marca de uma pausa de pequena duração", o que nos leva a pensar que essa idéia, para a fala, seria correta, ao passo que, para a escrita, a pausa seria difícil de ser marcada, já que não há critérios que estabeleçam essa interrupção na escrita. A mesma posição é adotada por Bechara (2001) quanto à pausa na oralidade, representada pela vírgula.

Piacentini (2009), em seu livro "Só vírgula", adota a perspectiva do uso da vírgula como um fenômeno que vai além da pausa. Ou seja, o uso em determinados casos, onde a idéia central é o uso da vírgula como intercalação e/ou deslocamento da ordem direta de frases e orações. Portanto, a autora define os casos do uso da vírgula, enfocados na construção lingüística e não em um critério de oralidade.

A atividade sugerida para a pesquisa levou em conta justamente o critério da construção lingüística. Nossa atividade, que se encontra em anexo, foi elaborada tendo em vista diversas etapas a serem alcançadas pelos alunos. Além disso, adotou-se, da mesma forma, a perspectiva de Franchi (2006), ao se utilizar uma atividade criativa, fazendo com que o aluno reflita sobre sua escrita. O próprio PCN (BRASIL,1998, p. 19) revela a função das atividades em sala de aula, que "têm como objetivo levar os alunos a pensar sobre a linguagem para poder compreendê-la e utilizá-la apropriadamente às situações e aos propósitos definidos". Tendo em vista esse objetivo, a atividade elaborada faz com que o aluno perceba que já possui o conhecimento acerca das vírgulas, embora, isso represente uma preocução quando lhe é exigido a aplicação do conteúdo internalizado. 


\section{A CONSTRUÇÃO DE UMA ATIVIDADE DIDÁTICA}

Lobato (2003) sugere três procedimentos para o ensino de gramática. O primeiro, que se denomina procedimento de descoberta, é o momento onde o aluno adquire toda a informação por si próprio, o que pode ser possível a partir do contato com dados da língua. Em seguida, para que o primeiro procedimento não se torne um processo lento, a autora sugere a metodologia da elicitação, que consiste em direcionar o aluno para formular pontos de vista, conclusões e conhecimento. E por fim, a técnica de resultados que trabalha com a assimilação do conteúdo pelos alunos, ou, na perspectiva da autora:

\footnotetext{
"o aluno verifica por si próprio que o ensino gramatical tem uma razão de ser, pois percebe que sentido obtém com tal ou tal estrutura. Ele então se dá conta de que esse tipo de estudo contribui para o seu domínio de estruturas e, em consequiência, para seu domínio do texto- que estruturas escolher de acordo com o significado que quer obter." (LOBATO, 2003, p. 7)
}

A atividade proposta para os alunos foi construída com base nas técnicas de Lobato (2003), tendo uma ênfase maior na metodologia da elicitação. Em um primeiro momento, há o texto com incentivo da descoberta por parte do aluno, para que seja alcançada a compreensão. Em seguida, a observação, a elicitação e por último a tarefa a ser realizada pelo aluno, sintetizando o conhecimento obtido. O papel do professor, por meio dessa atividade, é o de mediador da relação entre atividade e aluno. Segundo o PCN, a relação do professor com a atividade e o aluno seria:

“A mediação do professor, nesse sentido, cumpre o papel fundamental de organizar ações que possibilitem aos alunos o contato crítico e reflexivo com o diferente e o desvelamento dos implícitos das práticas de linguagem, inclusive sobre aspectos não percebidos inicialmente pelo grupo.” (BRASIL, 1998, p.48)

O texto incentivador é o primeiro contato do aluno com o conteúdo. Nele, o aluno será capaz de observar o uso da vírgula inserido em seu contexto. A observação é a separação de trechos comparativos, para que assim o próprio aluno consiga, intuitivamente, construir o conhecimento cognitivo. A elicitação é o momento onde o professor inicia uma série de perguntas que leva o aluno ao raciocínio e à construção de pensamento. A tarefa final consiste no momento em que o aluno aplicará o conhecimento formado. Segundo o PCN as atividades aplicadas aos alunos devem conter a "exercitação sobre os conteúdos estudados, de modo a permitir que o aluno se aproprie efetivamente das descobertas realizadas" (BRASIL, 1998, p. 79). Diante dessa justificativa, verifica-se a importância e a necessidade de que a atividade contenha a tarefa final. Muitas vezes, foi solicitado que o aluno 
construísse um conceito, sintetizando tudo o que aprendeu. Em outros momentos, procedeuse à aplicação de atividades em que o aluno deveria colocar as vírgulas nos devidos lugares em meio à composição textual, segundo o conhecimento formado.

Seguindo as instruções de Tomlinson e Masuhara (2005), nossa atividade sofreu avaliações e reformulações para que chegássemos a um modelo de material didático eficaz, criativo e que levasse o aluno a aprender o uso de vírgula por meio de um raciocínio e não de memorização.

Alguns casos de uso da vírgula foram escolhidos para a elaboração da atividade, pois, se fossem levados em conta todos os casos, a atividade se tornaria cansativa e o aluno, em uma aula, não conseguiria acompanhar todas as informações recebidas. Na primeira etapa, em anexo, a atividade se refere ao uso de vírgula em casos de adjuntos adverbiais. $\mathrm{Na}$ segunda etapa, contrastamos os casos de aposto e a relação entre sujeito e predicado. E na última etapa foi selecionada uma atividade em que o objetivo era demonstrar que a vírgula pode mudar o sentido da oração. Da mesma forma, acompanhando a atividade, foi solicitada ao aluno uma avaliação de todo o exercício realizado, levando em conta o que foi proveitoso, e o que não deveria constar como objetos de avaliação. A finalidade a ser alcançada, tomando por base o ponto de vista dos alunos, é a de avaliar nossa atividade sob o olhar de nosso público alvo.

\section{RESULTADOS}

A atividade foi aplicada seguindo dois contextos: no primeiro, a atividade foi aplicada em sala de aula, em uma escola pública do Distrito Federal, para alunos de $7^{\mathrm{a}}$ série $\left(8^{\circ}\right.$ ano), em fim de semestre, já no momento em que os alunos esperavam os resultados das disciplinas. O exercício foi aplicado aos estudantes pelos seus próprios professores de língua portuguesa. O segundo contexto é composto por alunos de diferentes séries: escolas públicas e particulares do Distrito Federal, que se dispuseram a realizar a atividade, de modo a “experimentar" o novo tipo de atividade didática e, nesse caso, denominamo-los voluntários.

O Gráfico 1 mostra a quantidade de exercícios realizados. Foram distribuídos um total de sessenta atividades, dentre as quais, vinte e sete foram respondidas e analisadas. Dezoito foram entregues incompletas. Três atividades foram entregues totalmente e branco, ou seja, não foram feitas. Dez foram produtos de cópias de outros alunos que haviam realizado a 
atividade. E, por fim, doze atividades que foram distribuídas não foram devolvidas pelos alunos. É importante salientar que, os alunos voluntários entregaram suas atividades totalmente respondidas, os dados do gráfico identificados como incompletos, não feitos, copiados ou não devolvidos se referem aos alunos do contexto 1. Uma possível hipótese para esse número de atividades não aproveitáveis à pesquisa, possa dever-se ao fato de que os alunos já não estavam em período efetivamente letivo, ou seja, em um momento em que apenas aguardavam suas notas para poderem retornar à suas casas. Dessa forma, os alunos não viam o exercício como uma utilidade para o ano letivo, mas como algo dispensável. Provavelmente, se a atividade fosse aplicada em um período que os alunos estivessem, ainda, em meio aos conteúdos curriculares, talvez obtivéssemos resultados melhores.

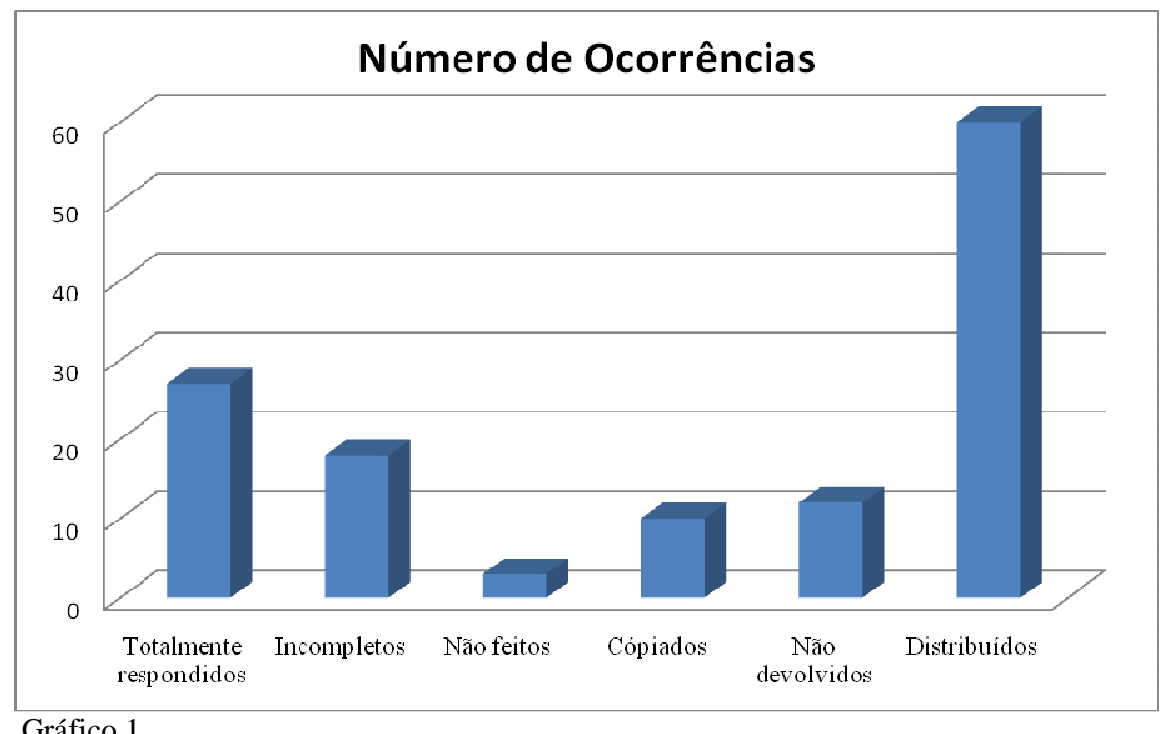

No gráfico 2, pode-se observar o resultado da atividade aplicada aos alunos de escola pública, sendo, grande maioria, alunos inseridos no contexto 1. O resultado considerado satisfatório foi o fato de que os alunos souberam construir sínteses lógicas do que foi observado na atividade, além de saberem, da mesma forma, identificar corretamente os usos da vírgula nas atividades denominadas tarefas finais. No caso dos alunos de escola pública, o percentual satisfatório foi baixo, havendo casos em que o aluno não soube formular adequadamente uma síntese do que lhe foi proposto, ou aplicou a vírgula em locais que não deveria como, por exemplo, entre sujeito e predicado. Entretanto, da parcela de exercícios satisfatórios, obtivemos respostas excelentes. Um detalhe a ser observado foi o fato de que, mesmo mostrando exemplos, fazendo comparações, elicitações, ou o aluno chegando à síntese e conclusão correta, em grande parte dos casos, os alunos justificavam o uso da 
vírgula baseado na concepção de uma marcação de pausa. Portanto, mesmo percebendo o porquê do uso, os alunos remetem suas respostas àquilo que sempre lhes foi ensinado.

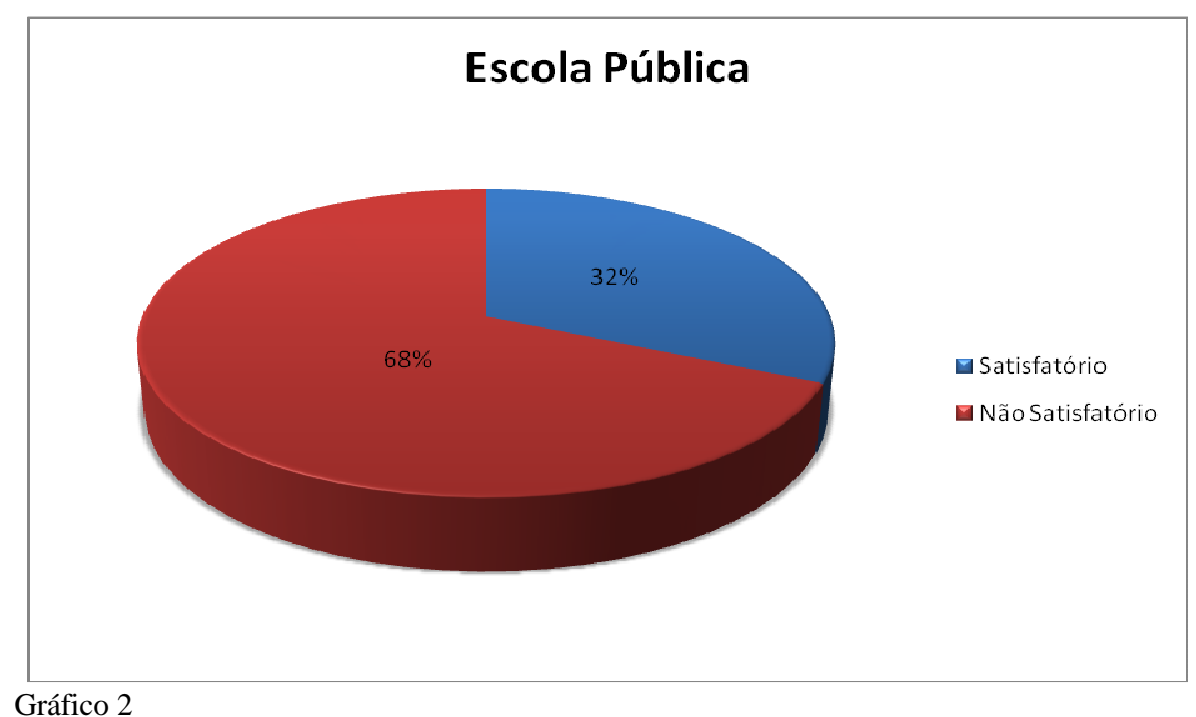

Em comparação ao rendimento dos alunos de escola pública na atividade, pode-se notar, por meio do gráfico 3 , que os alunos de escolar particular, que se voluntariaram responder a atividade, obtiveram uma porcentagem maior de atividades com resultados satisfatórios. Nesse caso, há que se levar em conta que o exercício não foi "exigido" aos alunos, como ocorreu no contexto 1, mas, ao contrário, lhes foi solicitado que "experimentassem" o novo exercício, afim de avaliarem o qual esse é realmente válido. Além desse fator, esses alunos fizeram as atividades em local reservado, onde não tinham interferências de outras pessoas.

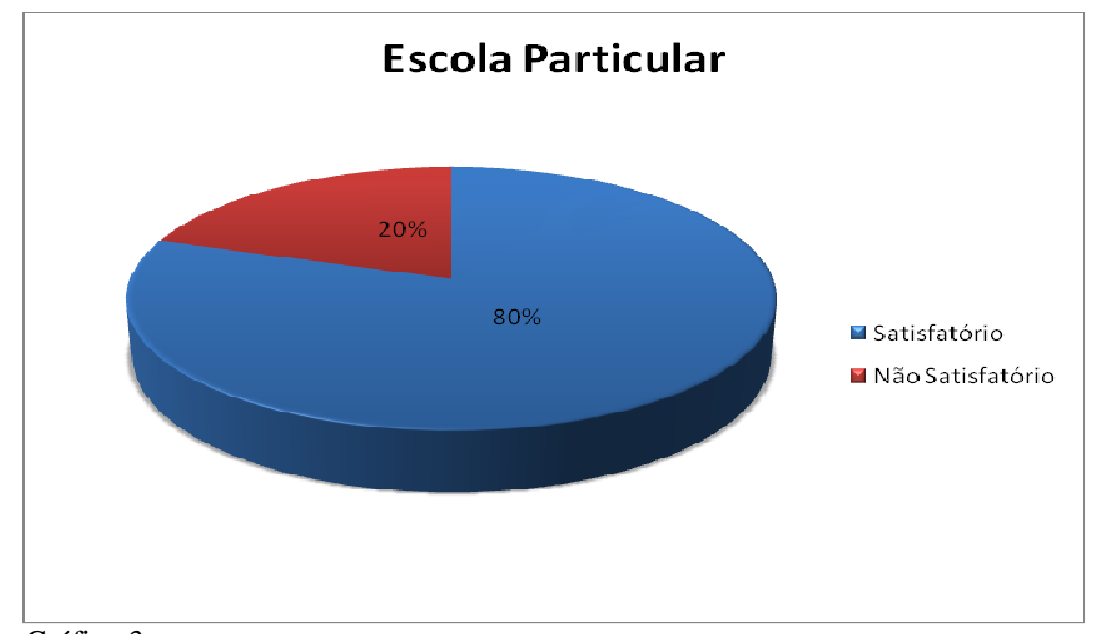

Gráfico 3 
A tabela abaixo demonstra o rendimento dos alunos de acordo com a série cursada. Justamente os alunos do contexto 1 foram os que apresentaram um número maior de atividades com rendimento não satisfatório. No caso, os alunos da $7^{\mathrm{a}}$ série $\left(8^{\mathrm{o}}\right.$ ano). Entretanto, há que se observar que, na faixa em questão, ocorreu o número maior de atividades analisadas. Dentre todas as séries, as atividades que obtivera melhores respostas foram as aplicadas no $3^{\circ}$ ano do ensino médio e na $5^{\mathrm{a}}$ série ( $6^{\circ}$ ano). Isso, talvez, se explique pelo fato de que no $3^{\circ}$ ano, espera-se que o aluno já tenha aprendido todos os conteúdos curriculares, pois esses estão em fase de preparação para o vestibular e demais processos seletivos. Por outro lado, a melhor explicação para o bom rendimento do aluno da $5^{\mathrm{a}}$ série ( $6^{\circ}$ ano) é a de que, entre as séries analisadas, essa é a que o aluno ainda se acostuma com a nova fase de ensino, pois acaba de egressar do ensino básico, de $1^{\mathrm{a}}$ a $4^{\mathrm{a}}$ série. Dessa forma, o aluno não tomou contato com um ensino de vírgula, permeado por bases conceituais da marcação de uma pausa, podendo, consequentemente, sistematizar melhor e obter conclusões sem a interferência do que já lhe foi ensinado.

\begin{tabular}{|c|c|c|}
\hline \multirow[t]{2}{*}{ Série } & \multicolumn{2}{|c|}{ Resultado (nº de alunos) } \\
\hline & Satisfatório & Não Satisfatório \\
\hline $5^{\text {a }}$ Série $\left(6^{0}\right.$ ano $)$ & 1 & $\varnothing$ \\
\hline $6^{\text {a }}$ Série $\left(7^{\circ}\right.$ ano $)$ & 1 & $\varnothing$ \\
\hline $7^{a}$ Série $\left(8^{0}\right.$ ano $)$ & 5 & 13 \\
\hline $8^{\mathrm{a}}$ Série $\left(9^{\circ}\right.$ ano $)$ & 1 & 1 \\
\hline $1^{0}$ ano do Ens. Médio. & 1 & $\varnothing$ \\
\hline $2^{\circ}$ ano do Ens. Médio. & 1 & 1 \\
\hline $3^{\circ}$ ano do Ens. Médio. & 1 & $\varnothing$ \\
\hline Ens. Supletivo & $\varnothing$ & 1 \\
\hline
\end{tabular}

Nas respostas dos alunos, houve casos de justificativas de respostas baseadas no conceito que sempre aprenderam de que a vírgula marca a pausa na oração. Inclusive, houve uma aluna que respondeu da seguinte forma: "O uso da vírgula é usado [sic] para indicar a pausa de qualquer texto.” Essa resposta foi dada após a elicitação e explicação do sistema SVO, ordem direta e dos adjuntos adverbiais. Dessa forma, não havia possibilidade de se remeter ao uso da vírgula como pausa pautado pela elicitação realizada inicialmente. $\mathrm{Na}$ mesma etapa de aprendizado, um outro aluno respondeu ao questionamento da seguinte maneira: "Na primeira sentença a vírgula representa uma pausa para dar um melhor destaque ao passado". Novamente, se faz menção à idéia de pausa que sempre nos foi transmitida. Em 
um terceiro caso, mesmo percebendo a vírgula após o adjunto adverbial, a aluna enfatizou, ainda, a pausa: "A vírgula aparece sempre depois do das [sic] orações a cada advérbio para dar uma pausa, e posição que ocupava um determinado sentido à oração". E continua: "Na primeira para separar o advérbio da frase. E a 3 porque é necessário [sic] uma pausa maior. A 2 porque a palavra 'ontem' ficou no final da frase." Nesse caso, a aluna percebeu o uso da vírgula em adjuntos adverbiais deslocados, entretanto, enfatizou, ainda, a vírgula como sendo uma pausa. Conceito que, certamente, foi construído pela reprodução da idéia tradicionalista do ensino de vírgula como uma pausa, e o ponto final, assim como o ponto-evírgula, como marcadores de pausa maior.

Em um outro exercício, o objetivo era o de demonstrar que a vírgula poderia mudar o sentido da oração, e uma aluna conseguiu encontrar um vocativo, que não havia sido percebido, e assim conseguiu justificar observação de maneira mais correta do que era esperado.

O exercício em que os alunos sentiram mais dificuldade foi a proposta de que se eles, em uma fábula, fossem capazes de conseguir achar os erros de vírgula. O argumento mais provável para essa dificuldade é a extensão do texto. Em uma nova proposta, poder-se-ia diminuir a extensão do texto escolhido, e ao longo do processo desse tipo de exercício, aumentar-se-ia extensão dos exercícios gradativamente. O exercício da $1^{\mathrm{a}}$ etapa "Vamos Praticar", onde o aluno teria que colocar as vírgulas, analisando o adjunto adverbial, não foi realizado pelos alunos por falta de atenção, pois não notaram que era um exercício. Nesse caso, para ser corrigido, poder-se-ia dar aumentar o tamanho da fonte e alterar a cor das letras para dar maior destaque.

O exercício que os alunos melhor desenvolveram foi o "Reflita" da $3^{\mathrm{a}}$ etapa, em que esses tinham que interpretar as sentenças e sintetizar o uso da vírgula. Nesse momento, houve excelentes explicações. Aliás, quando oferecia-se espaço para o aluno descrever o que observou, após ser eliciado, houveram conclusões riquíssimas, abarcando o entendimento do uso da vírgula nas determinas sentenças. No caso dos alunos que não atingiram um resultado satisfatório, pôde-se perceber que, apesar da conclusão não estar correta, houve uma linha de raciocínio que demonstrava que o aluno apreendeu certos pontos da análise esperada. Como, por exemplo, a resposta do aluno sobre a questão "Espaço do Cientista" da $2^{\text {a }}$ etapa: "Talves [sic] nos $1^{\circ}$ e $3^{\circ}$ exemplo [sic], não tenha sido usada a virgula, por serem frases curtas e continuas. $\mathrm{Na} 2^{\mathrm{a}}$ e $4^{\mathrm{a}}$ tem a adição de adjetivo." Sendo assim, o aluno não reconheceu o aposto, mas percebeu que havia a presença de adjetivos entre o sujeito e o predicado da 
oração. Dessa forma, houve uma percepção do porquê da vírgula estar presente nas sentenças indicadas.

$\mathrm{Na}$ avaliação da atividade realizada pelos alunos, obtivemos muitos elogios e sugestões. Determinada aluna avaliou da seguinte forma: "Todas as atividades foram ótimas, só não gostei da $1^{\mathrm{a}}$ etapa, um pouco difícil mais [sic] todas são muito boas!”. Como a atividade é uma nova proposta didática, deveríamos ter dado instruções antes do início de seu início, no intuito de que o aluno não viesse a ter dificuldades, o que se observou logo na primeira etapa, onde houve a falta de costume da aluna com a atividade.

Objeto de críticas por parte dos alunos foi a atividade referente ao uso da fábula, o que pode ser observado no posicionamento de um aluno: "Eu não gostei só da fábula por que me deixou confuso, mas fora isso eu gostei de tudo, eu acho que usando mais frases ficaria mais chamativo." A confusão a que o aluno se referiu foi reafirmada também por outra aluna, que especificou o motivo da confusão:

"Eu adorei as explicações e os espaços para podermos tentar responder antes da
explicação. Mas acho que me enrolei um pouco no desafio, meio que não sabia se
as frases foram consideradas parágrafos (aliás essa é uma dúvida que os
professores nunca tiram dos alunos)."

Além disso, a aluna em questão apontou um detalhe ao qual deveríamos nos atentar: a numeração das linhas para facilitar a "descoberta" do erro do uso da vírgula. Motivo que possivelmente explique o fato de os alunos não tem conseguido realizar a atividade. $\mathrm{O}$ próprio texto em si terá que se adequar à faixa etária dos alunos. Como nesse caso a atividade é um experimento, essa não destinou-se uma faixa etária alvo, sendo aplicada nas mais diversas etapas de ensino para analisar o desenvolvimento dos alunos. Porém, em uma sala de aula, o professor deverá adequar o texto à realidade de seus alunos. A própria fábula, em si, é um gênero que tende a ser difícilmente interpretado, o que faz com que muitos leitores não gostem de sua leitura, trazendo à tona a necessidade de se adequar o gênero ao contexto social e à capacidade dos alunos em questão.

A avaliação realizada pela aluna, citada anteriormente, nos trás um novo detalhe: ela relatou que gostou das explicações e dos espaços para responder diante às elicitações. Esse trecho faz com que a atividade seja válida, pois, a intenção de elicitação é a de levar o aluno à reflexão e obtenção de bons resultados. e além disso, conseguiu boa aceitação dos alunos que atestaram. De acordo com uma outra aluna, que também cita o espaço das explicações: "Eu gostei de algumas atividades como ade [sic] por a vírgula e as que tem que explicar". Esse trecho mostra que os alunos gostam de fazer suas próprias conclusões do que lhes foi 
apresentado, uma atividade mais válida do que a de reproduzir uma explicação que já lhe foi dada.

Por fim, tem-se a consideração de uma explanação surpreendente de uma outra aluna: "O que mais me interessou foi o uso da vírgula em três sentidos e ficou muito bom o trabalho, poderia acrescentar mais coisas, mais [sic] está ótimo." Além de realizar tudo que lhe foi proposto, a aluna ainda queria mais. Pode-se concluir daí, que a atividade não foi cansativa, pois foi dividida em três etapas somente, deixando os outros casos de uso da vírgula para outro momento do processo.

Por fim, uma avaliação sobre a atividade em sua totalidade foi: "Eu gostei muito da atividade, achei bem criativa e produtiva também. Gostei de toda a atividade, não tem muito o que mudar. Eu já tinha conhecimento do uso da vírgula, mais [sic] agora esta [sic] bem mais claro como utilizar a vírgula corretamente." Nosso intuito, no início da elaboração da atividade, era o de construir um exercício auto-explicativo aos alunos, que fosse criativo e os fizesse produzir reflexões e conclusões acerca do que lhes foi induzido. De acordo com a avaliação dessa aluna atingimos nossos objetivos.

\section{CONCLUSÃO}

A proposta de atividade didática aqui analisada não deve ser aplicada, ocasionalmente, ao longo de um ano letivo, somente. Mas, ao contrário, deve ser desenvolvida como um processo, para que o aluno se adapte ao tipo de tarefa, na qual não encontrará informações já prontas, mas terá que refletir e tirar suas próprias conclusões acerca dessas. O processo didático, que envolve esse tipo de atividade, fará com que o aluno se distancie da simples memorização dos conteúdos, passando a aprender realmente o que the foi ensinado. Vivemos em uma sociedade onde a facilidade é prezada. Dessa forma, o indivíduo não está acostumado a refletir e a pensar, mas sim decorar. Ou seja, o indivíduo é levado a conhecer, aplicar e saber a regra, mas não aprende, de fato, o porquê de essa ser como é.

Assim sendo, o estudo que representa o uso da vírgula não se caracteriza uma exceção à busca pela facilidade e praticidade por parte da sociedade. Como a modalidade falada é mais "simples" do que a escrita, a explicação mais fácil a respeito do uso da vírgula se centrou em questões fonológicas. Porém, a realidade não é essa. Quando redigimos um 
texto, não utilizamos a vírgula pensando em uma pausa da fala, pois seria um critério muito abstrato, e por essa razão as pessoas preferem não usar a vírgula para não errar.

Dessa forma, é necessária uma reformulação educacional no que tange alguns conceitos no estudo da língua portuguesa, que ainda são disseminados pela escola. Se os professores se atentarem às novas correntes teóricas, e até mesmo lerem as orientações dos PCN's, perceberão que a nova proposta de ensino consiste justamente em levar o aluno a descobrir, refletir e produzir, proposta essa que buscamos ilustrar e exemplificar na atividade aqui apresentada. Entretanto, o ajuste das atividades caracterizam-se uma necessidade constante em relação aos objetivos pretendidos, fazendo com que o aluno seja levado a pensar sobre sua prática no aprendizado.

\section{REFERENCIAS BIBLIOGRÁFICAS}

BECHARA, Evanildo. Gramática Escolar da Língua Portuguesa. Rio de Janeiro: Lucerna, 2001.

BOGDAN, R.C.\& BIKLEN, S. K Qualitative research for education: An introduction to theory and methods. 3ra. Ed. Needham Heights: Thiro, 1982.

BRASIL. Ministério da Educação. Secretaria de Educação Fundamental. Parâmetros Curriculares nacionais: terceiro e quarto ciclos do ensino fundamental: língua portuguesa. Secretaria da educação Fundamental. Brasília: MEC/SEF, 1998.

CHOMSKY, N. A Linguagem e sua configuração. In: CHOMSKY, N. Arquitetura da linguagem. Organizadores Nirmalangshu Mukherji, Bibudhendra Narayan Patnaik, Rama Kant Agnihotri. Bauru, SP: Edusc, 2008. p. 15-53.

CUNHA, Celso. CINTRA, Lindley. Nova Gramática do Português Contemporâneo. 3. ed. Rio de Janeiro: Nova Fronteira, 2001. p. 644.

ERICKSON, F. Qualitative Methods in Research in Teaching and Learning. New York: Macmillan Publishing Company. Vol. 2. Tradução de Stela Maris Bortoni, 1986.

FRANCHI, C. Mas o que é mesmo “gramática”?, SP:Parábola, 2006. Pág. 11-99.

LOBATO, Lúcia. O que os professores de ensino fundamental precisam saber sobre lingüística. 2003 
PIACENTINI, Maria Teresa de Queiroz. Só vírgula: método fácil em 20 lições. 3 ed. Edufcar, 2009.

RIOS, Guilherme. Considerações sobre letramento, escolarização e avaliação educacional. In: RESENDE, V. M. \& PEREIRA, F. H; Práticas Sócioculturais e discurso: Debates Transdisciplinares. Portugal: LabCom Books 2010.

O que é letramento? Não publicado.

SOARES, Magda. Letramento e alfabetização: as muitas facetas. Revista Brasileira de Educação, Rio de Janeiro: Autores Associados, n. 25, 2003. Disponível em: <http://www.scielo.br/pdf/rbedu/n25/n25a01.pdf >. Acesso em: 13 de novembro de 2010.

TOMLINSON, B. \& MASUHARA, H. A Elaboração de Materiais para cursos de idiomas. São Paulo: Special Book Services Livraria, 2005. 86 p.

TRAVAGLiA, L. C.; ARAÚJO, M. H. S \& ALVIM, M. T. F. Metodologia e prática de ensino de língua portuguesa. 4 ed. Uberlândia: EDUFU, 2007.

\section{BIBLIOGRAFIA CONSULTADA}

Abordagens teóricas. Mestrado de informática aplicada à educação. Disponível em: <http://www.nce.ufrj.br/ginape/publicacoes/trabalhos/renatomaterial/psicolinguistica.htm>. Acesso em: 31 de maio de 2010.

BRASIL. MEC. Portal do professor. Disponível em: < http://portaldo professor.mec. gov.br>. Acesso em 28 de julho de 2010.

BRASIL. Ministério da Educação. Secretaria de Educação Fundamental. Parâmetros Curriculares nacionais: ensino médio: linguagens, códigos e suas tecnologias . Secretaria da educação. Fundamental. Brasília: MEC/SEF, 1998.

FARACO, Carlos Alberto. Norma culta brasileira: desatando alguns nós. São Paulo: Parábola, 2008

SONCIN, Geovana Carina Neri. Os usos da vírgula em textos de alunos da última série do ensino fundamental. Disponível em: <http://prope.unesp.br/xxi_cic/27_36869843856 .pdf> , acesso dia 15/08/2010. 
Escola:

Aluno (a):

Idade:

Série:

\section{USOS DA VÍRGULA}

\section{1a Etapa}

A língua portuguesa é constituída pelo sistema SVO. O "S" significa sujeito, o "V" significa verbo e o " $\mathrm{O}$ " significa objeto.

Então na frase: "Eu comi bolo"
\[ \text { S } 0 \]

Eu - é o sujeito; comi - é o verbo e bolo é o objeto.

Agora observe: "Eu comi bolo ontem"

S V 0 adj. Adverbial

Temos aqui a formação SVO + adjunto adverbial. Lembrando que o adjunto adverbial é um termo acessório, que modifica o sentido de um verbo, de um adjetivo ou de um advérbio. No caso da frase, o adjunto adverbial é "ontem".

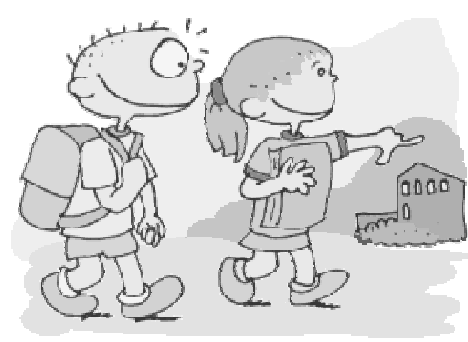

\section{AGORA OBSERVE}

1- Ontem, Juquinha chegou cedo à escola.

2- Juquinha chegou cedo à escola ontem.

3- Juquinha chegou, ontem, cedo à escola.

Responda oralmente: Nas três sentenças acima você observou a palavra em negrito? Trata-se de um adjunto adverbial. Mas você percebeu que essa palavra ocupou diferentes posições nas orações? Houve alguma modificação no significado das orações? O que ocorreu?

Agora observe o uso das vírgulas, você saberia explicar por que elas estão presentes em duas das três orações apresentadas? Reflita. 
Você seria capaz de escrever a explicação do uso da vírgula nas sentenças 1 e 3 ? E também de escrever o porquê da oração 2 não possuir vírgulas?

\section{Vamos Praticar?}

Com base em sua análise feita acima, você seria capaz de colocar as vírgulas em seus devidos lugares nas seguintes orações?

Atenção! Há mais de um caso de adjunto adverbial.

1- Na semana passada fui de ônibus para a escola.

2- Fui de ônibus na semana passada para a escola.

3- Fui de ônibus para a escola na semana passada.

\section{Fazendo algumas conclusões:}

Como você deve ter percebido o adjunto adverbial, quando é apresentado na forma direta, não necessita do uso de vírgulas, como na oração número 3 em que você acabou de resolver.

Já na oração número 1 o adjunto adverbial é apresentado antes do sujeito, ocorrendo então um deslocamento da ordem direta. $\mathrm{O}$ mesmo ocorre na oração número 2 onde o adjunto adverbial foi deslocado para o centro da oração. Você também conseguiu chegar a essas conclusões? Que bom! Então continuemos em uma nova etapa! 


\section{$2^{\mathrm{a}}$ Etapa}

Leia atentamente a tirinha abaixo:
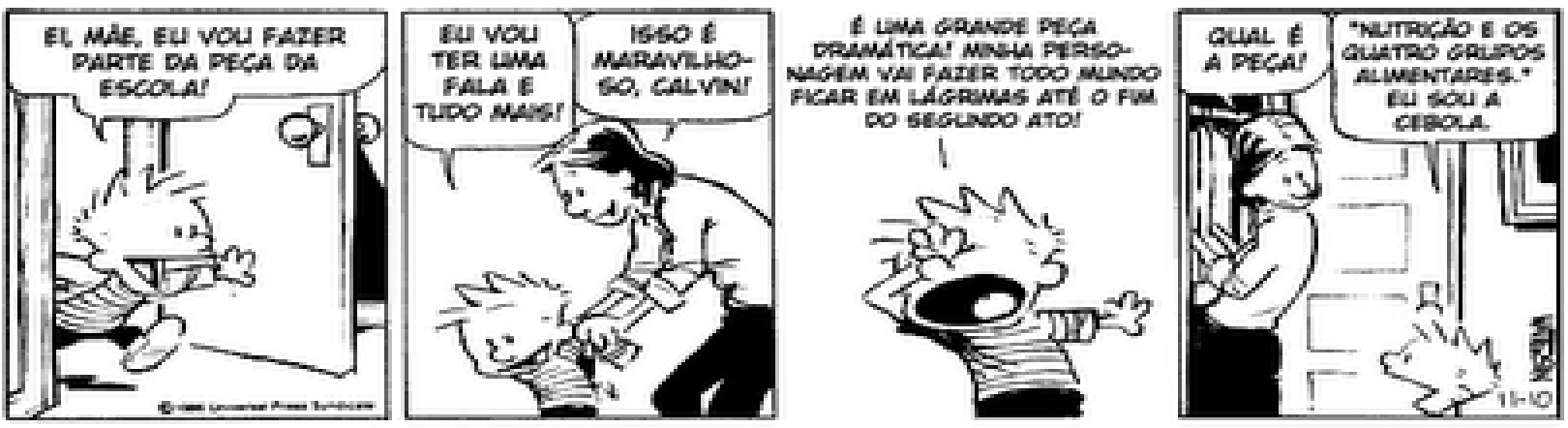

Observe com mais atenção!

1- A mãe de Calvin ficou feliz com a notícia.

2- A mãe de Calvin, pessoa bondosa e paciente, ajudou seu filho a retirar seu casaco.

3- Calvin fará o papel de cebola na peça.

4- Calvin, menino esperto e irônico, fará o papel de cebola na peça

\section{Para refletir...}

Nos exemplos da página anterior temos referências a Calvin, personagem norte americano de histórias em quadrinhos, e à sua mãe. No primeiro e terceiro caso, não temos nenhum caso de vírgula, por quê? Não havia necessidade? No segundo e quarto caso, temos vírgulas separando alguma referência à mãe de Calvin e a Calvin, respectivamente, por que isso ocorreu?

\section{Espaço do Cientista!}

Você é capaz de criar hipóteses? Explique os dois casos acima, levando em conta que ocorrem casos de relação entre sujeito e predicado e presença de aposto. 


\section{E Agora?}

Você conseguiu identificar os casos acima? Nos casos 1 e 3 temos a referência de caso entre sujeito e predicado, onde não há a necessidade do uso da vírgula. E nos exemplos 2 e 4, temos a presença de aposto, que é uma explicação, especificação, resumo ou enumeração do termo anterior, por isso a necessidade da vírgula, para não misturar a explicação com os outros termos, entendeu? Agora sim podemos ir para a última etapa.

\section{3a Etapa}

Estamos chegando ao fim de nossas observações.

Uma vez, havia escrito em um muro de escola, após as férias, a seguinte mensagem:

1- Voltei linda!

Será que o estudante que escreveu isso era realmente uma menina que queria exaltar seu novo padrão de beleza? Mas se talvez fosse um menino que tivesse escrito, será que ele não queria dizer:

2- Voltei, linda!

Uma vírgula pode causar uma grande confusão no que você quer expressar. E por isso é que devemos compreender bem o seu uso.

\section{Reflita...}

Qual é a diferença entre as duas orações? Por que ocorre o caso da vírgula na segunda sentença, mas não na primeira? Você é capaz de escrever isso? Utilize o espaço abaixo.

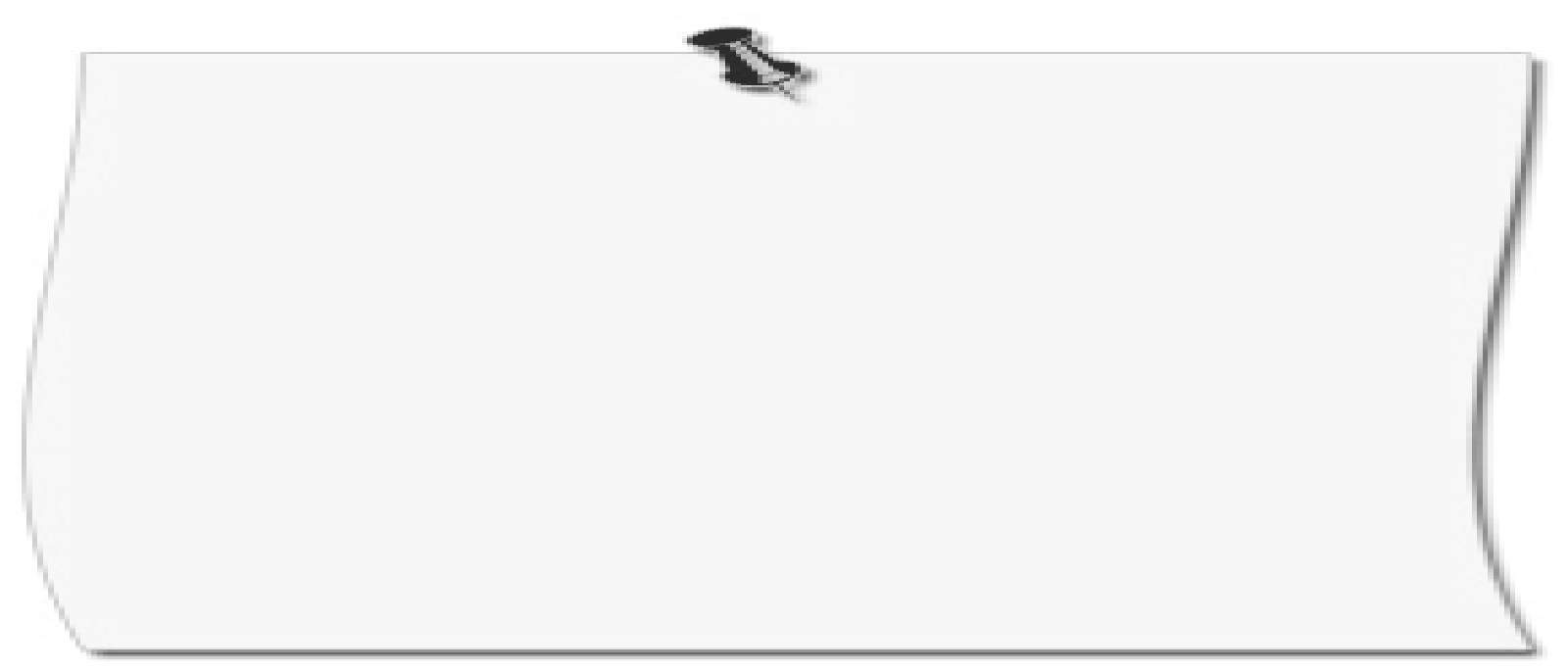




\section{Vamos Praticar?}

A seguir há uma fábula de Esopo. Porém, nosso editor, ao redigir a história, esqueceu-se de como utilizar a vírgula, deixando locais onde a vírgula era necessária sem, e em outros locais colocou vírgula onde não era necessário. Identifique e corrija os erros de nosso editor. Preste atenção no quadro de dicas:

- Nos 1ㅇ e 4으 parágrafos há casos de adjuntos adverbiais deslocados sem vírgula.

Identifique-os e acrescente as vírgulas.

- No 1 o parágrafo há 2 casos de aposto sem o uso devido da vírgula. Identifique-os e acrescente as vírgulas em seus devidos lugares

- Nos 3ำ e 4ำ parágrafos, há vírgula separando sujeito e predicado. Retire-as.

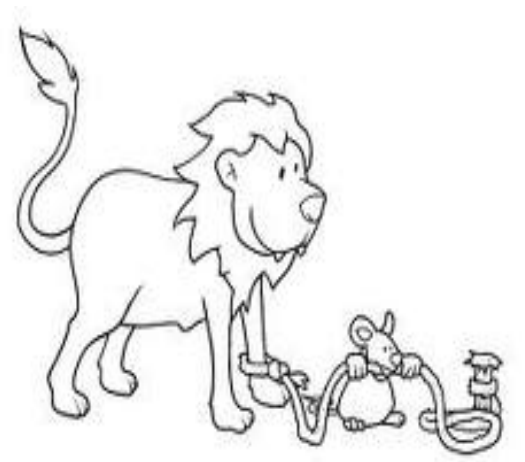

\section{O LEÃO E O RATO}

"Numa manhã ensolarada um Leão enorme e bravo dormia sossegado, quando foi despertado por um Rato pequeno e ágil que passou correndo sobre seu rosto. Com um bote ágil ele o pegou, e estava pronto para matá-lo, ao que o Rato suplicou:

- Senhor Leão, se me poupar tenho certeza que um dia poderIhe-ei retribuir sua bondade.

Rindo por achar ridícula a idéia, assim mesmo, ele resolveu libertá-lo. Aconteceu que, pouco tempo depois, o Leão, caiu numa armadilha colocada por caçadores. Preso ao chão, amarrado por fortes cordas, sequer podia mexer-se. O Rato, reconhecendo seu rugido, se aproximou e roeu as cordas até deixá-lo livre. Então disse:

- Senhor Leão, o senhor riu da simples idéia de que eu seria capaz um dia de retribuir seu favor. Mas agora sabe, que mesmo um pequeno Rato, é capaz de fazer um favor a um poderoso Leão.

\section{Moral da História:}

Nenhum ato gentileza é coisa vã. Não podemos julgar a importância de um favor, pela aparência do benfeitor"

Autor: Esopo 


\section{POR FIM... O ÚLTIMO DESAFIO}

Você seria capaz de avaliar essa atividade sobre o uso da vírgula? Escreva, no espaço abaixo, tudo o que você gostou ou não nas atividades e explicações propostas. Diga o que poderia melhorar. E por fim, através da atividade você poderia inferir se aprendeu a utilizar as vírgulas? Escreva tudo no espaço abaixo. E no fim circule a nota que você daria à atividade. Este espaço é seu! E desde já, muito obrigada.
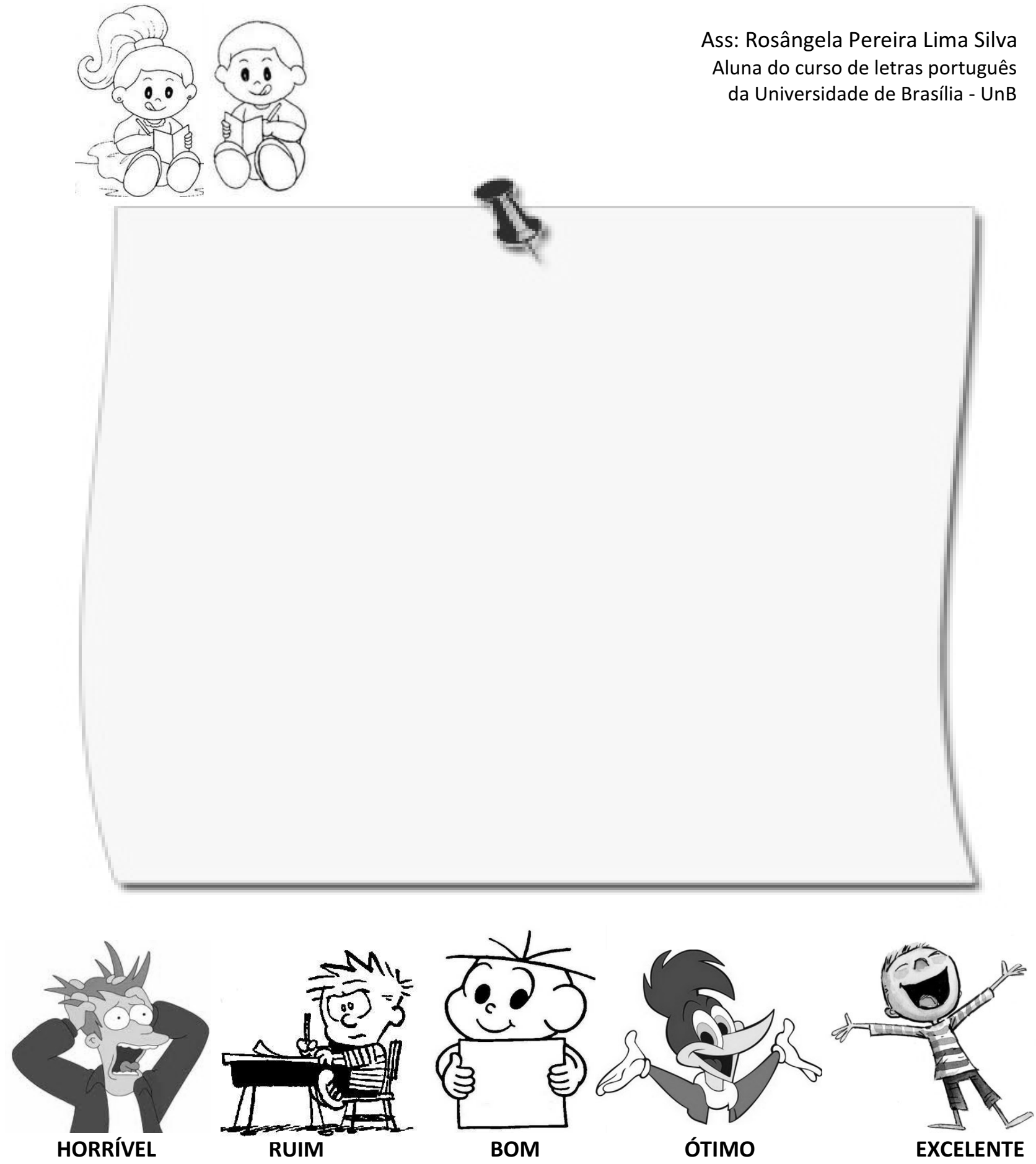